\title{
The Development of ICD Adaptations and Modifications as Background to a Potential Saudi Arabia's National Version
}

\author{
Musaed Ali Alharbi ${ }^{1,2}$, Godfrey Isouard ${ }^{1,3} \&$ Barry Tolchard ${ }^{1,4}$ \\ ${ }^{1}$ University of New of New England, Armidale, Australia \\ ${ }^{2}$ Ministry of Health in Kingdom of Saudi Arabia \\ ${ }^{3}$ Australasian College of Health Service Management (ACHSM), Sydney, Australia \\ ${ }^{4}$ University of Huddersfield, Queensgate, Huddersfield, UK \\ Correspondence: Musaed Ali Alharbi, School of Health, University of New England, Australia, Elm Avenue, \\ Armidale NSW 2351. E-mail: musaed52@gmail.com
}

\author{
Received: August 12, 2019 Accepted: September 13, 2019 Online Published: September 19, 2019 \\ doi:10.5539/gjhs.v11n11p158 \\ URL: https://doi.org/10.5539/gjhs.v11n11p158
}

\begin{abstract}
Modified national versions of the WHO's International Statistical Classification of Diseases, current version ICD-10 with ICD-11 coming into effect in January 2022, have become the standard in many countries for diagnosis and procedure coding to facilitate the submission of medical billing and reimbursement by health insurers. The WHO ICD-10 exists purely as a coded classification of disease. It has no related classification of procedures and lacks the clinical level of diagnostic specificity necessary for the documentation of individual clinical cases and the associated prescribed therapies and interventions, particularly surgical cases. Historically, the US clinical modification of ICD-9, known as ICD-9-CM, established the trend. Australia adopted ICD-9-CM, later adapted it to Australian clinical specifications, and after the launch of the WHO ICD-10 produced the current Australian modification ICD-10-AM, used under license by many other countries. This paper examines a work in progress, rather than offering an academic critique, to illustrate the evolution of national clinical modications with particular reference to those of the United States, Australia and Thailand. The selection is based on the historical ICD-9-CM connection of the US and Australia, and the fact that Thailand is a more advanced developing nation like Saudi Arabia. The study parameters include the Saudi national healthcare system which has not previously employed a classification clinical coding, despite the wealthy developing healthcare system. Nations using their own modification face the burden of upgrading. Saudi Arabia plans to implement the national Australian modification, rather than creating a Saudi national modification.
\end{abstract}

Keywords: clinical coding, clinical modification, ICD-10, national modification, WHO

\section{Introduction}

The International Statistical Classification of Diseases (ICD) published by the World Health Organization (WHO) to classify morbidity and mortality, represented a revolution in medical classification. It does not represent a clinical classification, particularly not having a related procedures or interventions classification. The diagnosis and prescribed treatment of an individual patient health episode involves an individual diagnosis of a disease or injury and a series of potential events. Some diagnoses may only be complete after pathological or radiological assessment, while others may initially indicate surgical or other procedural resolution. Hence, the clinical modifications of the WHO ICD versions occur at a national level related to the particular national system of healthcare and the relationship of initial diagnoses to the required treatment, based on the national health information management and medical insurance practices (Jetté et al., 2010).

While clinical coding is a relatively new term that developed in the 1970s in the era of ICD-9, medical coding had long been used as a statistical practice in recording the causes of mortality and grouping these to produce mortality statistics. The early classifications were known as the 'International List of Causes of Death' (ILCD) covering the period, 1893 to 1947, before the WHO took custody of this classification and released its first version in 1948. This became known as ICD-6, and was the successor to the fifth version of the ILCD. Despite the emergence of the clinical modifications the WHO ICD versions continue to offer contemporary benefits for the classification death and disease. The change to the usage of clinical modifications and clinical coding in medical practice is neatly 
described by Rosemary Roberts, director of the Australian NCCC that produce the ICD-10-AM Australian modification: "The connection between the codes and the health dollar has turned the spotlight on coding previously used only to identify groups of similar patients for research, utilization studies or quality assurance" (Roberts, Innes, \& Walker, 1998, p. S32). Thus, coding became clinical coding, based on a clinical modification of the WHO classification, which has evolved from version to version, with each subsequent release improving its purpose in the healthcare system. The generational revolution of this clinical coding classification has thus far involved 10 stages, with each successive stage becoming a unique universality index that heralded a new version of the classification system (Moriyama et al., 2011).

The need to implement a classification of diseases and clinical coding in Saudi Arabia is a development of the continuous efforts of the Saudi government to improve the efficiency of its healthcare systems, especially for its list of affiliated hospitals and the need to secure additional healthcare financing through health insurance (Alharbi, 2018). The Australian national modification of the clinical coding for diseases and procedures was selected by the Saudi government to be the national classification and clinical coding system for diagnoses and procedures for all three healthcare providers (public, private, and other government healthcare providers) (Alharbi, Tolchard, \& Isouard, 2019).

Despite the global importance of creating a national clinical coding modification for healthcare organizations, which has led to a proliferation of studies highlighting this issue, in Saudi Arabia, there is no reliable evidence on this issue even underpinning it by presenting other countries' experiences. Thus, this paper aims to remedy this gap in the literature by exploring a gap in the Saudi literature on the advantages of establishing a Saudi national clinical modification, rather than applying the Australian modification. This paper examines the case studies of the United States (US) and Australia (as developed nations) and Thailand (as a developing nation) to depict the importance of establishing a Saudi national version of the ICD-10. However, before analyzing and justifying the importance of the national modifications of the ICD-10, it is essential to overview the clinical modifications and the national versions of ICD-10.

\section{Method}

The systematic search strategy methodology used in this study aimed to understand a national phenomenon in Saudi's healthcare system. A systematic review method serves as the most effective research method for this paper as it helps to gain a deeper understanding of the research issue through an in-depth understanding of the positive effects of establishing a national modification of clinical coding on in Saudi's healthcare system for more effective and accurate clinical classification. The systematic method search was performed online, searching Google Scholar database between 1996 and 2019. The review of literature evaluated peer-reviewed books, theses, articles and reports related to ICD-10. Related studies in the English language were extracted based on the following keyword rule:

\section{- "Clinical Modification" AND (ICD-10-CM OR ICD-10-AM OR ICD-10-TM)}

Studies were selected in this step based on the principal eligibility criteria, in line with the purpose of this review: studies published on the relevant area of clinical coding, dealing with its national modifications. Hence, this process took place via the following inclusion steps:

1) screening the research title as the elementary inclusion criteria step

2) screening the research abstract using the final inclusion criteria

Other sources included the primary documentation on ICD of the WHO and national healthcare organizations, as well as webpage information from consultancies, vendors, and training organizations. The national health information management websites such as the American Health Information Management Association and Health Information Management Association of Australia also offer useful databases, as well as the use of bibliographies of some of the articles.

The search identified 3400 records in Google Scholar. It was found that the majority related to the use of ICD classification data in clinical studies; therefore, they were excluded based on a quick screening of the titles (or abstract in some cases). The search identified 13 studies in other primary documentation records. There were two duplicates. On assessment of 52 materials were included for full material review and 42 were included in the review. 


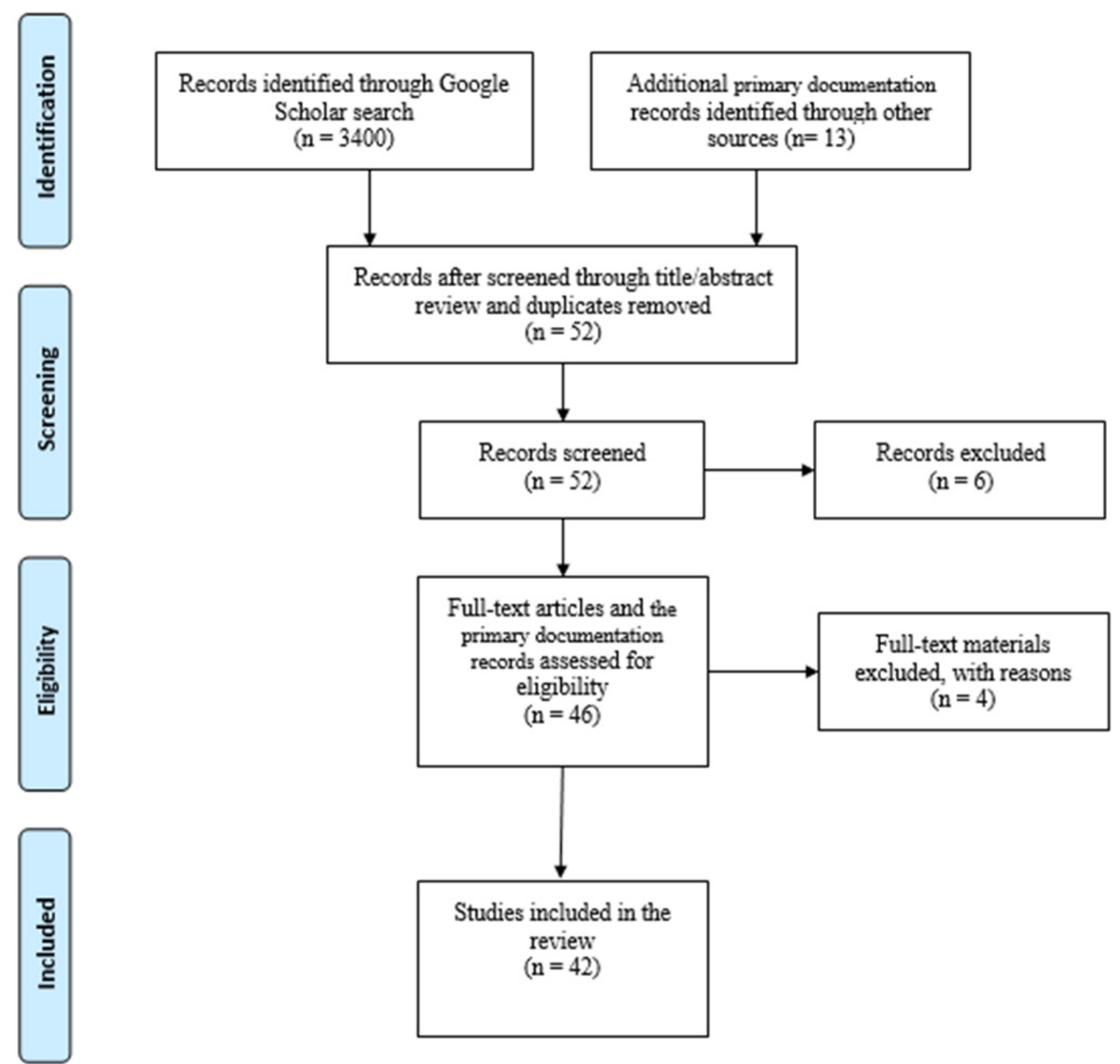

Figure 1. Flow Chart of the Review Strategy

\section{Results}

\subsection{ICD Adaptations and Modifications}

User reports from as early as ICD-6 indicated the need for national adjustments to the morbidity classification, mainly related to specific national clinical standards and practices, as well as translation of terminology (Moriyama et al., 2011). The ICDA-8 became the first adaptation for hospital diagnostic data, replaced in 1979 by ICD-9-CM, the first clinical modification of the WHO ICD classification. It was only officially replaced by ICD-10-CM as recently as October 2015 (Monestime, 2015; Centers for Disease Control and Prevention, 2016). Before the release of ICD-10-CM, Australia produced ICD-10-AM and Canada ICD-10-CA, while, in Europe, ICD-10-GM represents a German-language modification and ICD-10-nL is a Dutch modification. In Asia, Korea uses ICD-10-KM, while Thailand developed ICD-10-TM, which extends the coverage of many regional diseases. Additionally, Thailand created a separate ICD-10-TTM which is based on Thai traditional medicine and therapies (Jetté et al., 2010; World Health Organization, 2015).

\subsection{United States Adaptations and Clinical Modifications}

In 1979, The International Classification of Diseases, 9th Revision, Clinical Modification (ICD-9-CM), based on the WHO ICD-9 officially supplanted the ICDA-8 adaptations. The introduction of ICD-9-CM provides the following description of a clinical modification:

"The term "clinical" is used to emphasize the modification's intent: to serve as a useful tool in the area of classification of morbidity data for indexing of medical records, medical care review, and ambulatory and other 
medical care programs, as well as for basic health statistics. To describe the clinical picture of the patient, the codes must be more precise than those needed only for statistical groupings and trend analysis." (Buck, 2015, p.1).

In describing the diagnosis classification, the introduction of ICD-9-CM emphasizes its complete compatibility with the WHO ICD-9 for international statistical purposes stating: "A few fourth-digit codes were created in existing three-digit rubrics only when the necessary detail could not be accommodated by the use of a fifth-digit sub-classification."

The WHO released the ICPM procedure classification simultaneously with ICD-9, as a series of supplementary documents, termed fascicles and covering medical procedures, interventions, and therapy types including surgery, radiology, pathology, and others. The procedure classification of ICD-9-CM was derived from Fascicle V of the ICPM, the surgical classification. Australia and Canada also adopted the US ICD-9-CM.

Like ICD-9-CM, the US clinical modification, ICD-10-CM derived from the WHO ICD-10, is intended for classification and coding of morbidity, based on the physician's clinical diagnosis of the patient in any consultation or treatment setting. The ICD-10-CM codes greatly outnumber those of the ICD-9-CM and are considered 'intelligent codes' in that they provide meaning for users (Steindel, 2010).

Alongside the ICD-10-CM diagnosis classification, the US has produced a separate procedures classification, the International Classification of Diseases 10th Revision Procedure Coding System (ICD-10-PCS) (Topaz, Shafran-Topaz, \& Bowles, 2013). The ICD-10-PCS was developed by the Centers for Medicare and Medicaid Services (CMS), solely for use in US inpatient hospital settings. The new Procedure Coding System (PCS) uses seven alphanumeric digits, while the ICD-9-CM coding system used three or four numeric digits (Centers for Medicare and Medicaid Services, 2015). The first character refers to the category of medical procedure, followed by numbers that indicate the body system, root operation, body part, approach and device used in the procedure (Averill, Mullin, Steinbeck, Goldfield, \& Grant, 1998; Steindel, 2010). To avoid confusion with the digits 0 and 1, the letters $\mathrm{O}$ and I are omitted There are approximately 87,000 procedure codes, all of which are seven characters in length (Chute, Huff, Ferguson, Walker, \& Halamka, 2012; Utter, Cox, Owens, \& Romano, 2013). The ICD-10-PCS is used by US Health Information Management (HIM) professionals as the standard tool for classifying and coding inpatient operations and procedures (Manchikanti, Falco, \& Hirsch, 2011; Mullin, 1999). The schedule is divided into 16 different procedure categories, such as nuclear medicine, radiation oncology, medical and surgical, physical rehabilitation, and diagnostic audiology (Utter et al., 2013).

\subsection{Development of the Australian Modification}

Australia has developed its own national clinical modification based on the WHO version of ICD-10, known as ICD-10-AM/ACHI/ACS and used to assign codes for diagnoses and procedures (Shepheard, 2009). The acronym, 'AM', denotes Australian modification, 'ACHI' Australian Classification of Health Interventions and 'ACS' Australian Coding Standards. Groenewold (2016, p. 45): "ICD-10-AM is used to classify diagnoses for all inpatient episodes of care. The ACHI is used to classify procedures and interventions performed during inpatient episodes of care. Clinical coders use the ACS as a guide to assigning ICD-10-AM/ACHI codes."

Medical coding in Australia commenced in 1907, when the Australian Bureau of Statistics first used the ILCD to classify causes of mortalities. Over the past 50 years, constant advances have been made in the clinical coding field in Australia. Paralleling the development of national healthcare in 1968, Australian health organizations expanded the content of ICD-8 to include nationally oriented healthcare diagnoses, procedures, guidelines, and medical research. On the release of the US clinical modification, ICD-9-CM, Australia switched to this version as its basic classificatory system (Roberts, Innes, \& Walker, 1998).

As a classificatory system, ICD-10-AM/ACHI/ACS comprehensively reflects the development of the national healthcare system yet retains adaptability to alternative systems. Accordingly, the Australian modification is being used by numerous other countries, confirming its inherent quality, as well as its relative ease of implementation and the product support offered for smaller nations, as opposed to the mammoth ICD-10-CM, which supports the diversity of competitive systems and privatized funding across the US. It was against this background of product flexibility, national needs design, and technical support that the Saudi MOH based its decision to implement ICD-10-AM (Jetté et al., 2010).

\subsubsection{Australian Modification}

Historically, ICD-10-AM replaced ICD-9-CM, in the Australian Capital Territory, New South Wales, Victoria and the Northern Territory in 1998, with other Australian states following shortly afterwards. At the same time, the Australian Refined Diagnosis-related Group (AR-DRG) classification system, based on the ICD-10-AM and ACHI codes, replaced the Australian National Diagnosis-related Groups (AN-DRG) which had been used since 
1992, for health funding, as well as an extension of clinical coding for purposes besides reimbursement, such as epidemiological data and research (Weber, 2004).

The ICD-10-AM is published by the National Centre for Classification in Health $(\mathrm{NCCH})$, housed at the University of Sydney, which is also responsible for updating the classification schedules (Doyle \& Dimitropoulos, 2009). The second and third editions were published in 2000 and 2002 (Murphy, Wiley, Clifton, \& McDonagh, 2004 ) and the ninth edition in 2015 . While, in practice, the term refers to the full package; namely diagnosis codes, procedure codes, coding standards, and diagnosis-related groups used in Australia and licensed to other countries, as in the case of Saudi Arabia, ICD-10-AM strictly refers to the diagnosis codes structured in two parts; a tabular list of diseases and an accompanying index (Australian Consortium for Classification Development, 2017).

Licensing of other nations to use the Australian modification package is done through individual country contract with the IHPA, an independent Australian government agency established as part of the National Health Reform Agreement (NHRA) in 2011. The IHPA also uses hospital data to determine funding levels for national public hospital services, using the process termed Activity Based Funding (ABF). Current licensees are Bahrain, Bosnia \& Herzegovina, Bulgaria, Ireland, Lithuania, Macedonia, Moldova, New Zealand, Montenegro, Qatar, Saudi Arabia, Serbia, Singapore, Slovenia, Turkey, and Ukraine, although many of these nations only use the AR-DRG component (Independent Hospital Pricing Authority, 2015).

\subsubsection{Australian Classification of Health Interventions}

The NCCH used the Medicare Benefits Schedule (MBS) to create a procedural classification system, the ACHI. The ACHI was formerly known as the Medicare Benefits Schedule-Extended, which was used by HIM professionals as an inpatient coding system to classify procedures and interventions (Barnes \& Krinsky, 1999). The ACHI codes comprise seven digits, of which digits 1 to 5 denote the MBS item numbers, while the remaining two digits represent specific interventions. The ACHI fulfils the same purpose in Australian healthcare as ICD-10-PCS in the US. It consists of two parts: a tabular list of interventions and an accompanying alphabetic index (Australian Consortium for Classification Development, 2017).

\subsubsection{Australian Coding Standards}

The ACS was created to ensure a consistent national standard in the application of ICD-10-AM and ACHI in Australian public and private hospitals. The ACS includes guidelines for the use of the procedure and diagnosis codes by clinical coders and other users of clinical codes and is available in hardcopy and e-book format (Australian Consortium for Classification Development, 2017). The ACS also governs the use of AR-DRGs. Australia's integration of coding schedule methods has produced a synthesized composite system that reflects the national development of the Australian modification of ICD-10 healthcare practice.

\subsubsection{Casemix}

Casemix refers to classification into homogeneous groups based on the use of resources and forms the central classificatory component of the AR-DRG. It provides not only a basis for reimbursement, but also a consistent classification of patient types and related treatments (Health Information Management Association of Australia, 2015). Söderlund (1994, p. 225) observed: "Measuring actual changes in health status, or health-related quality of life, must remain the gold standard for hospital product quantification." Casemix is essentially a quantification and costing of hospital care that provides a superior method and far greater time efficiency than itemised billing. While the US and Australia use the DRG, the United Kingdom prefers the Health Resource Group. Alternative approaches used in specific contexts are Facility Mix and Service Mix. Casemix incorporates a classificatory system and schedule of payments. Without the payment component, casemix can be applied to quantify service delivery, quality, and other healthcare assessments (Webster, 1996).

\subsubsection{Australian Diagnosis-Related Groups}

In 1992, Australia created a coded medical payment classification system of the casemix variety, the Australian National Diagnosis-Related Groups (AN-DRG), to group and calculate specific health cost weights in health insurance systems and is derived from the US system (Duckett, 2000). The AN-DRG was replaced in 1998 by the Australian Refined Diagnosis-Related Groups. All diagnoses and procedures listed in the clinical documentation of hospital inpatient records are coded by specialist clinical coders using the ICD-10-AM/ACHI/ACS. This coded information, together with individual demographic data (age, gender and length, of stay), is used to allocate an AR-DRG class by the clinical coder, hospital or state health authority (National Casemix and Classification Centre, 2016). The health cost weight is based on a combination of patient demographic data, such as age and employment aspects, and groupings of diagnoses and related procedures. This process eliminates the old-fashioned itemized billing system, in which individual items, such as prescribed medicines, dressings, special nursing requirements, 
and length of hospitalization, were accounted for in the final billing. The groupings are based on the averaging of historical data. Saudi Arabia has recently begun the process of introducing this medical payment system across all healthcare providers (Lucyk, Lu, Sajobi, \& Quan, 2016).

\subsubsection{The Practice of Clinical Coding in Australia's Modern Technological Hospitals}

As aforementioned, the WHO International Statistical Classification of Diseases and Related Health Problems (ICD) series, currently in its 10th revision (ICD-10), and the directly related national modifications such as ICD-10-AM, ICD-10-CM, and ICD-10-TM, have become the international standard for documenting and coding patient diagnoses and procedures, initially to facilitate the billing of consultations and treatments, as claims for reimbursement from health insurers.

The assigning of codes is based on the clinical documentation of a single health episode of an admitted patient as written up in the patient's file or recorded in an electronic health record (EHR). The clinical documentation commences with the admittance diagnosis of the examining physician, who may call for an X-ray or blood test before finalizing the diagnosis and therefore the documentation in the patient file may include reports from radiology and pathology and may extend to ward nurse reports and surgical interventions and a pharmacy report on the prescribed medicines. Hence, the decisions made by the coder during the coding process are based on a combination of knowledge of anatomy, pathology, general medical practice and interventions, applied to an understanding of the diagnosis and procedure classifications. Depending on the systems employed in the hospital, the coding assigned may still be done on paper or inputted directly into an EHR. Similarly, the submission to the insurer may still be mailed in hard copy format and the reimbursement returned by mail in the form of a cheque to the recipient, though this process lacks security and the global standard is in the electronic form via technological systems. While it is not yet applicable to Saudi hospitals, healthcare institutions around the world are converting to EHRs and commencing with the clinical documentation of the physician, all information is being entered directly into a computer software form.

The coded data originating as the record of an individual patient's single healthcare episode, can be far more easily stored in the electronic format than as a hard copy paper file and may be more easily retrieved when the patient suffers a further healthcare episode. Further, as useful data for producing regional, national and international statistics that provide insights into community and public health and for healthcare research, the electronic format is clearly more accessible and more easily compiled.

The following is an example of the patient record of a young woman referred for gynecological assessment who has been examined outside the hospital and the examining initial gynecologist is querying the possibility of an ovarian cyst. She has undergone a keyhole laparoscopy, under general anesthetic to assess the existence of a cyst. The cyst has been confirmed and removed for histological laboratory assessment. It has been classified as non-cancerous. In practice, as in this case, the diagnosis is often not possible before the procedure. In this example, the actual diagnosis has been the last step, and could only be established after the procedures. 
Table 1. ICD-10-AM/ACHI coding example

\begin{tabular}{|c|c|}
\hline \multicolumn{2}{|l|}{ Australian healthcare and clinical coding in practice } \\
\hline \multicolumn{2}{|c|}{$\begin{array}{l}\text { ICD-10-AM/ACHI Diagnosis and Procedure Classification and Coding; Gynecologist referred patient covered by Medicare for } \\
\text { hospital admission }\end{array}$} \\
\hline $\begin{array}{l}\text { Referral Diagnosis } \\
\text { [Clinical documentation] }\end{array}$ & $\begin{array}{l}\text { 24-year-old female presents with ultrasound evidence of an } \\
\text { asymptomatic query; Right ovarian dermoid noted during } \\
\text { screening for possible polycystic ovary }\end{array}$ \\
\hline \multicolumn{2}{|l|}{ Clinical coding } \\
\hline Classification & Assigned code \\
\hline Surgical & Main Procedure \\
\hline $\begin{array}{l}\text { Gynecological Procedures / Ovary/ Excision/ Other excision } \\
\text { procedures on ovary/ Laparoscopic ovarian cystectomy, } \\
\text { unilateral }\end{array}$ & Laparoscopy 35638-04 \\
\hline Anesthetists & Anesthetic \\
\hline General anaesthesia, ASA 19 & 92514-19 \\
\hline Histology & Pathology Laboratory Procedure \\
\hline $\mathrm{M}=$ morphology of neoplasms/teratoma & M9080/0 \\
\hline Discharge diagnosis & D-27 \\
\hline Benign neoplasm of the ovary & \\
\hline
\end{tabular}

\subsection{ICD-10-TM and Thai DRG Development and Relevance}

While the US and Australia differ enormously in size, they are both culturally Western, English-speaking nations that were relatively recently settled, and comprise developed economies. In contrast, Saudi Arabia has an ancient Islamic cultural heritage that represents the heart of Islam, even though the region has recently been transformed economically, and very rapidly, in becoming one of the world's leading producers of oil (Tripp \& North, 2003). Similarly, Thailand has an ancient Buddhist heritage and was ruled as a monarchy until 1932. Since then, it has been mainly under military rule, interspersed with short bursts of democracy. The Vietnam War saw an influx of US dollars into the economy, which led to urbanization, a higher standard of living for some, and a proliferation of Western culture (Wyatt, 2003).

The Thai Medical Informatics Society was established in 1991 through the insight of a consortium of computer science academics and graduates from the 12 medical schools in the country. ICD-10 was adopted in 1994 and used throughout the private and state health sectors by 1997 (Paoin, n.d.). There was soon recognition - particularly in the tropical regions - that ICD-10 lacked codes for certain regional health issues, such as necrotising fasciitis, dengue shock syndrome, and cobra and green pit viper snake bite. Thus, a nationally representative Thai modification project was launched in 2000, followed by a pilot study in 25 hospitals, after which the ICD-10-TM became the national healthcare classificatory system alongside the Thai DRG (Paoin, 2006). Thailand introduced a universal coverage scheme in 2001, providing healthcare to all citizens not covered by health insurance. This scheme was originally touted as 'thirty Baht treats all diseases' (less than US\$1); however, co-payment was eliminated in 2006 (Evans et al., 2012; Hughes \& Leethongdee, 2007).

\subsubsection{Development of ICD-10 for Thai Traditional Medicine Services}

In recognition of its cultural heritage, which includes an age-old traditional medical system, Thailand has constructed a corollary ICD-10-TTM ('Thai traditional medicine') coding consisting of 528 diagnosis and 60 procedure codes. Procedures include herbal drugs, Nuad Thai (Thai massage), herbal compression, herbal steam and sauna, warm compression, postpartum warm salt pot compression, and Thai traditional postpartum care (Visithanon, 2012). Thai medicine is based on the Buddhist view of the human body, which ICD-10-TTM incorporates into Thailand's national healthcare system. The WHO has estimated that three-quarters of the world's population relies on traditional medicine-mainly medicinal plants - for general treatments. With the renewed Western in traditional therapies, this short discussion on ICD-10 TTM was included because it may have future relevance for Saudi Arabia, where a large section of the population still employ traditional Arabic and Islamic medicine for specific conditions (Azaizeh, Saad, Cooper, \& Said, 2010). 
Based on this assessment of the global use of traditional medicine-either exclusively or in conjunction with allopathic (conventional Western) medicine - the WHO consulted with stakeholders and leading practitioners in the fields of traditional medicine or complementary and alternative medicine and health information systems, and developed a collaborative project plan to produce an international standard terminology and classification system for traditional medicine. The project aims to produce an international standard for use with electronic health records that will also serve as a standard for scientific comparisons. This includes an International Classification of Traditional Medicine, an International Standard Terminologies of Traditional Medicine, and a web portal linking these to the WHO Family of International Classifications (International Classification of Traditional Medicine, 2010; Morris, Gomes, \& Allen, 2012).

\section{Discussion}

This study covered the emergence of national modifications of ICD-10, due to the need for healthcare industry-related diagnosis and procedure classification that forms the basis of the application of casemix for individual patient reimbursement by insurance and hospital funding, formerly covered by the government. As Saudi Arabia has become a licensee of the Australian package, the individual components of ICD-10-AM were examined, given the differences in patterns of disease among countries. Other national modifications examined were the US ICD-10-CM and Thai ICD-10-TM, the latter having been included because Saudi Arabia and Thailand exhibit certain similarities as developing countries. ICD-10-TTM, the Thai classification of ICD-10 for traditional medicine and associated procedures, which are integrally practiced together with allopathic medicine in the country was also briefly examined. Saudi Arabia also has a tradition of traditional medicine. Should the reason ever arise that Saudi Arabia may need to develop its classification and coding schedule, the Thai classifications may well provide models to be examined. In this study, it was established that in less than two decades following the establishment of the Thai Medical Informatics Society, not only has Thailand produced its modification of ICD-10 but, further, a modification based on Thai traditional medicine, ICD-10 for TTM. The general comparative evaluation of Australian and the US literature on ICD-10 and its associated modifications are representative of the Developed Nations, while the literature of Thailand, representing another Developing Nation, provides a basis for inferring the value of establishing a national modification of clinical coding in Saudi's healthcare system. The account also shows conclusively that no Saudi literature has yet examined a potential Saudi clinical classification, thus, the current study fills a void in Saudi healthcare literature.

\section{Conclusion}

This review explored the benefits of national clinical modifications of the basic WHO ICD version. It adopted an approach of reviewing the literature to gain an in-depth understanding of the research issue. The research objective was achieved by defining the meaning of the national modifications and highlighting their value, given the differences in patterns and treatments of diseases in different global regions. The research indicated that the evolution of the national modifications had promoted the demand by specialists to produce a national version that led to the successful implementation of the Thai national modification. The study also the background to other national modifications through the historical overview of the development of the initial adaptations of ICD- 8 to produce ICDA-8. Our conclusion is that, while the ILCD to ICD-10 development over nearly two centuries has been embodied in the practice of healthcare in major nations, and some developing nations in its latest version, it has been absent from the Saudi health care system, indicating a conscious factor that may have an influence. Thus, the review provides an examination of the what Saudi Arabia has lacked, which in time should be developed according to its own clinical usage and prevalence of diseases.

\section{Competing Interests Statement}

The authors declare that there are no competing or potential conflicts of interest.

\section{References}

Alharbi, M. A. (2018). The Status Quo of Health Information Technology and Health Information Management Efficiency in Saudi Arabia: A Narrative Review. International Journal of Health Research and Innovation, 6(1), 11-23. https://hdl.handle.net/1959.11/23228

Alharbi, M. A., Tolchard, B., \& Isouard, G. (2019). Developing and Measuring the Reliability and Validity of the Factors Influencing the Implementation of ICD-10-AM and Clinical Coding in Saudi Public Hospitals. Global Journal of Health Science, 11(10), 1-15. https://doi.org/10.5539/gjhs.v11n10p1

Australian Consortium for Classification Development. (2017). The international statistical classification of diseases and related health problems, tenth revision, australian modification (ICD-10-AM/ACHI/ACS) (Tenth ed.). Darlinghurst, NSW: Independent Hospital Pricing Authority. Retrieved from 
https://www.accd.net.au/Icd10.aspx

Averill, R. F., Mullin, R., Steinbeck, B., Goldfield, N., \& Grant, T. (1998). Development of the ICD-10 Procedure Coding System (ICD-10-PCS). Journal of American Health Information Management Association, 69(5), 65-72.

Azaizeh, H., Saad, B., Cooper, E., \& Said, O. (2010). Traditional Arabic and Islamic medicine, a re-emerging health aid. Evidence-Based Complementary and Alternative Medicine, 7(4), 419-424. https://doi.org/10.1093/ecam/nen039

Barnes, C., \& Krinsky, T. (1999). Classifications systems, casemix and data quality: Implications for international management and research applications. Casemix Quarterly, 1(2), 1-13.

Buck, C. J. (2015). 2015 ICD-9-CM for Hospitals, Volumes 1, 2 and 3 Professional Edition-E-Book. Elsevier Health Sciences.

Burns, N., \& Grove, S. K. (2010). Understanding Nursing Research - eBook: Building an Evidence-Based Practice. St. Louis, MO: Saunders/Elsevier.

Centers for Disease Control and Prevention. (2016). International Classification of Diseases - 9 - CM, (1979). Scientific Data Documentation. Retrieved 02 August, 2017, from https://wonder.cdc.gov/wonder/sci_data/codes/icd9/type_txt/icd9cm.asp

Centers for Medicare and Medicaid Services. (2015). ICD-10-CM/PCS The next generation of coding. Retrieved from https://www.thenationalcouncil.org/wp-content/uploads/2013/01/ICD-10TheNextGenerationofCoding.pdf

Chute, C. G., Huff, S. M., Ferguson, J. A., Walker, J. M., \& Halamka, J. D. (2012). There are important reasons for delaying implementation of the new ICD-10 coding system. Health Affairs, 31(4), 836-842. https://doi.org/10.1377/hlthaff.2011.1258

Doyle, K., \& Dimitropoulos, V. (2009). Keeping our classification up to date. Health Information Management Journal, 38(1), 50-52. https://doi.org/10.1177/183335830903800107

Duckett, S. (2000). The development of Australian refined diagnosis related groups: the Australian inpatient casemix classification. Casemix Quarterly, 2(4), 115-120.

Evans, T. G., Chowdhury, A., Evans, D., Fidler, A., Lindelow, M., Mills, A., . . Team, T. R (2012). Thailand's Universal Coverage Scheme Successes and Challenges - An Independent assessment of the first 10 years (2001-2011). Nonthaburi, Thailand: Health Insurance System Research Office.

Groenewold, E. (2016). Measuring the effectiveness of feedback in clinical coding training. Assessment Zone, 45. In Siddiqui, Z., \& Wijesinghe, R. (2016). Assessment Zone issue 3. This is an excellent resource produced by my students and worth sharing it.

Health Information Management Association of Australia. (2015). FAQs - What is ICD-10-AM, ACHI and ACS? Retrieved from http://www.himaa2.org.au/education/index.php?q=node/81

Hughes, D., \& Leethongdee, S. (2007). Universal coverage in the land of smiles: lessons from Thailand's 30 Baht health reforms. Health Affairs, 26(4), 999-1008. https://doi.org/10.1377/hlthaff.26.4.999

Independent Hospital Pricing Authority. (2015). AR-DRG classification system. Retrieved from https://www.ihpa.gov.au/what-we-do/products/AR-DRG-classification-system

International Classification of Traditional Medicine. (2010). ICTM. Retrieved from https://sites.google.com/site/whoictm/.

Jetté, N., Quan, H., Hemmelgarn, B., Drosler, S., Maass, C., Moskal, L., . . Jakob, R. (2010). The development, evolution, and modifications of ICD-10: challenges to the international comparability of morbidity data. Medical care, 48(12), 1105-1110. https://doi.org/10.1097/MLR.0b013e3181ef9d3e

Lucyk, K., Lu, M., Sajobi, T., \& Quan, H. (2016). Disease Groupings: What are They, How are They Used, and How Do They Compare Internationally? Perspectives in Health Information Management. 1-12.

Manchikanti, L., Falco, F. J., \& Hirsch, J. A. (2011). Necessity and implications of ICD-10: Facts and fallacies. Pain physician, 14(5), E405-E425.

Monestime, J. (2015). ICD-10-CM Implementation Strategies: An Application of the Technology Acceptance Model (Doctoral dissertation, Walden University).

Moriyama, I. M., Loy, R. M., Robb-Smith, A. H., Rosenberg, H. M., \& Hoyert, D. L. (2011). History of the 
statistical classification of diseases and causes of death. Hyattsville, MD: U.S. Department of Health and Human Services, Centers for Disease Control and Prevention, National Center for Health Statistics.

Morris, W, Gomes, S, Allen, M. (2012). International classification of traditional medicine. Glob Adv Health Med. 1(4), 38-41. https://doi.org/10.7453/gahmj.2012.1.4.005

Mullin, R. L. (1999). Brief History of ICD-10-PCS. American Health Information Management Association, 70(9), $1-3$.

Murphy, D., Wiley, M. M., Clifton, A., \& McDonagh, D. (2004). Updating clinical coding in Ireland: Options and opportunities. Dublin: The Economic and Social Research Institute (ESRI).

National Casemix and Classification Centre. (2016). About Casemix. Retrieved from https://nccc.uow.edu.au/casemix/aboutcasemix/index.html

Paoin, W. (2006). Development of ICD-10 Thai Modification in Thailand. Retrieved from http://apps.who.int/classifications/apps/icd/meetings/2006meeting/WHOFIC2006\%20-\%20C406\%20-\%20 Development\%20of\%20ICD-10\%20Thai\%20Modification\%20in\%20Thailand.pdf.

Paoin, W. (n.d.). Thai Medical Informatics Association and medical informatics activity in Thailand. Retrieved from http://citeseerx.ist.psu.edu/viewdoc/download?doi=10.1.1.545.5159\&rep=rep1\&type=pdf.

Roberts, R. F., Innes, K. C., \& Walker, S. M. (1998). Introducing ICD-10-AM in Australian hospitals. The Medical Journal of Australia, 169, S32-35. https://doi.org/10.5694/j.1326-5377.1998.tb123473.x

Shepheard, J. (2009). Health Classification-a Complex World. Health Information Management Journal, 38(1), 4. https://doi.org/10.1177/183335830903800101

Söderlund, N. (1994). Product definition for healthcare contracting: an overview of approaches to measuring hospital output with reference to the UK internal market. Journal of Epidemiology \& Community Health, 48(3), 224-231. https://doi.org/10.1136/jech.48.3.224

Steindel, S. J. (2010). International classification of diseases, clinical modification and procedure coding system: descriptive overview of the next generation HIPAA code sets. Journal of the American Medical Informatics Association, 17(3), 274-282. https://doi.org/10.1136/jamia.2009.001230

Topaz, M., Shafran-Topaz, L., \& Bowles, K. H. (2013). ICD-9 to ICD-10: evolution, revolution, and current debates in the United States. Perspectives in health information management/, American Health Information Management Association, 10(Spring).

Tripp, H., \& North, P. (2003). Culture Shock!: Saudi Arabia. Portland: Graphic Arts Center Publishing Company.

Utter, G. H., Cox, G. L., Owens, P. L., \& Romano, P. S. (2013). Challenges and opportunities with ICD-10-CM/PCS: implications for surgical research involving administrative data. Journal of the American College of Surgeons, 217(3), 516-526. https://doi.org/10.1016/j.jamcollsurg.2013.04.029

Visithanon, K. (2012). Development of ICD-10 For Thai Traditional Medicine Services (ICD-10 for TTM). Retrieved http://www.whofic-apn.com/pdf_files/2013thai/06_ICD-10\%20for\%20Thai\%20Traditional\%20Medicne\%2 OServices.pdf

Weber, R. G. (2004). Recognizing the ICD-10-GM, German Coding Guidelines, and German Coders. Recognizing the ICD-10-GM, German Coding Guidelines, and German Coders/AHIMA, American Health Information Management Association.

Webster, F. (1996). Development of a casemix classification system for inpatient rehabilitation services. Australian Health Review, 19(3), 81-92. https://doi.org/10.1071/AH960081a

World Health Organization. (2015). Case-based Payment Systems for Hospital Funding in Asia An Investigation of Current Status and Future Directions: An Investigation of Current Status and Future Directions. Paris: OECD Publishing.

Wyatt, D. K. (2003). Thailand: A short history. New Haven, CT: Yale University Press.

\section{Copyrights}

Copyright for this article is retained by the author(s), with first publication rights granted to the journal.

This is an open-access article distributed under the terms and conditions of the Creative Commons Attribution license (http://creativecommons.org/licenses/by/4.0/). 